\title{
The Level of Tendency of Students and Their Attitudes Towards Reading at The Stage of Primary Education and Intermediate it in The City of Dar Chiouck In Algeria -Field Study-
}

\author{
Aicha Alla ${ }^{1}$ \\ University of Djelfa, Algeria \\ psyc.aicha@gmail.com
}

Received: $3^{\text {td }}$ Nov 2020 Revised: $14^{\text {th }}$ Nov 2020 Accepted: $16^{\text {th }}$ Nov $2020 \quad$ DOI: https://doi.org/10.31559/CCSE2020.1.2.5

Abstract: The objective of the present study is to identify the level of tendency of students and their attitudes towards reading at the stage of primary education and intermediate it in the city of Dar chiouck in Algeria, as well as the nature of the differences according to the following demographic variables: (GenderEducational stage ), and the sample consisted of 246 individuals, with females $=$ 123 and males $=123$, and primary education $=106$ pupils intermediate education=140 pupils; The study tools included a scale prepared by Adawi Abd al-Zahra and Attia Samira 2008, has been addressed by using standard statistical methods spss 25 program, the descriptive approach was adopted, resulted the study at the following results: first: The level of tendency of students and their attitudes towards reading at the stage of primary education and intermediate it in the city of Dar chiouck in Algeria stage median, second: There aren't statistically significant differences at $(\alpha=0.05)$ in the level of tendency of students and their attitudes towards reading at the stage of primary education and intermediate it in the city of Dar chiouck in Algeria according to the variable gender, third: There's statistically significant differences at $(\alpha=0.05)$ in the level of tendency of students and their attitudes towards reading at the stage of primary education and intermediate it in the city of Dar chiouck in Algeria according to the variable Educational stage in favor primary education.

Keywords: Tendency; Reading; pupils; primary education; intermediate education.

${ }^{1}$ Corresponding author

Aicha Alla

University of Djelfa, Algeria

E-mail: psyc.aicha@gmail.com 


\section{Introduction}

To know the level of orientation of students and their attitudes towards reading requires that the learner be interactive, positive and will only happen by provoking his motives, activating him, and making him feel that his efficiency increases, and his efforts are not wasted in vain, which requires, as the development of Arabic language education is seen by the members of the Language groups, faculty professors concerned with linguistic and educational studies, Arabic language supervisors and teachers that reading lacks the identification, attention and development of basic skills and abilities, as the majority of students go to use electronic means such as the internet-enabled computer for viewing and reading in varying proportions. In different ways, reading and skills have received great attention because they are the open window of knowledge and it is one of the most important tools of education, and in light of this importance, its learning has received great attention as it provides students with the ability to personally fit, through which the reasons for entertainment and enjoyment are available through stories and books, and they develop many skills as well (Al-Haiali, 2011: 4).

Reading is therefore one of the most important language skills taught in school. It contains other sub-skills, which are of different types, and in order for the student to achieve success in any subject he must be able to read and there are a number of skills that are necessary to increase the effectiveness of reading, and if we mention reading, we do not mean just repeating words, but we mean to get ideas and master them and come up with new experiences (Hassan, 2003:15). The study of the reality of the learner in reading proves that there is a weakness in it, although its image and reasons vary from person to person.

The reading was highly regarded in the Book of God, and the Arabs boasted of the book as a new sitter and nations agreed on its importance in the lives of individuals, and the development of their societies, and in this research the reading was addressed at the beginning by recognizing its nature, concept, importance, functions and skills, Its objectives at the primary and middle stage, and its relationship to the characteristics of growth in these two phases, the reading process is complex, involving a set of skills, and it involves many mental processes of understanding, remembering, concluding, and evaluating, and the reading process consists of events that are unobserved in themselves, and that What we see only from them is the excitements, which occur at the beginning, which are the 
vision of the written symbol, and the responses that eventually come in the form of behavior that expresses a person's understanding of what they read (Al-Shammari,2020: 116); As for the mental events that occur within the individual, and mediate between the triggers and responses, psychologists are still trying to reveal them scientifically, which is very complex (Mousa, 2007:35); And reading as one of the language skills is important to the individual, it provides him with the necessary information that helps him solve many of the problems he faces, pushes him to meditate and think, and provokes the spirit of initiative, innovation and criticism. (Al-Lafi. 2000: 157). Reading at its highest levels opens the way for linking experiences, discovering relationships and using thinking and imagination broadly to develop an individual's experiences and abilities. The relationship between reading and thinking seems to be one of influence and influence. Each affect and influences the other; when one reads, one exercises thinking, and then his thinking skills grow, and when he thinks, his knowledge expands and his abilities that enable him to absorb and add to the reader' (Al-bakr, 2013: 18). Accordingly, the research problem can be formulated through the following questions:

- What is the level of tendency of students and their attitudes towards reading at the stage of primary education and intermediate it in the city of Dar chiouck in Algeria to be median?

- Are there statistically significant differences at the level of significance $(\alpha=0.05)$ in the level of tendency of students and their attitudes towards reading at the stage of primary education and intermediate it in the city of Dar chiouck in Algeria according to the variable gender?

- Are there statistically significant differences at the level of significance $(\alpha=0.05)$ in the level of tendency of students and their attitudes towards reading at the stage of primary education and intermediate it in the city of Dar chiouck in Algeria according to the variable Educational stage?

Research hypotheses:

Based on the literature of previous studies, the research hypotheses were formulated as follows:

- We expect the level of tendency of students and their attitudes towards reading at the stage of primary education and intermediate it in the city of Dar chiouck in Algeria stage to be median.

- There are statistically significant differences at the level of significance $(\alpha=0.05)$ in the level of tendency of students and their attitudes towards reading at the stage of primary education and 
intermediate it in the city of Dar chiouck in Algeria according to the variable gender.

- There are statistically significant differences at the level of significance $(\alpha=0.05)$ in the level of tendency of students and their attitudes towards reading at the stage of primary education and intermediate it in the city of Dar chiouck in Algeria according to the variable Educational stage.

The importance of choosing the subject of the research:

The importance of the topic lies in the following points:

- Many psychological and educational researchers have addressed the interest of many psychologists and educators for this topic.

- Enriching the scientific library with such studies that meet the scientific and academic requirements, and based on the literature of the importance of reading and the extent of its popularity.

- Using the research results to guide the studies of researchers who will address the same topic in their studies.

- Through the urgent need to do both theoretically and in practice, and the need for this type of research to develop the educational process and school support.
Research objectives:

The objectives of the research are to highlight the importance of this vital subject (the level of pupils' tendency to read) at the primary and basic education levels and to identify pupils' attitudes towards reading, and the extent to which pupils' attitudes towards reading differ according to gender and school level variables.

Research Concepts and Procedural Terms:

First-The concept of tendencies: according to Nazzal is the behavior of students that reflects their interest in the practice of reading (Nazzal, 2002:79) while Wilson sees the tendency as a relatively constant emotional organization that gives attention and attention to a particular subject with the participation of a mental and emotional cognitive group and feels some satisfaction in its practice (Adawi, 2008: 262.)

Second-The concept of reading: It was Defined by (Dowing; 1982) "It is the process by which a child can analyze a sequence of phrases in printed or narrated text and accurately understand the message in the text", and was defined by alHasan (2005) " as intellectual mental activity that involves many factors, aiming at its basis to link the speaking language with the writing language" (Al-Hassan, 2005: 11). It is defined procedurally as a process 
that defines pupils of the fifth grade and the first grade intermediate on symbols and the pronunciation of written words and sentences as contained in the book reading or reading books in libraries, and the era states that reading is a process of thinking no less than that used by the author of the text read by the reader, both there is organization, understanding, analysis, composition, governance, problem solving, selection and inference, comparison of data, criticism, linkage, conclusion and generalization (Abde al-Bari, 1999: 38.).

Reading Principles:

In a report (Reader Nation), Anderson and others define five general principles that determine the nature of reading:

- It is a structural process, as there is no text that fully explains itself.

- It should be fluency because there is a close link between fluency and the ability to understand the reading.

- It is a strategic process that requires a flexible reader who can change the way he reads, depending on the complexity of the text, and the reader's understanding of its subject.

- Learning to read needs motivation, since learning to read well takes many years, requires a lot of effort and selfconfidence.
- Reading is an ever-growing skill that can be mastered once and at a certain age, but is a skill that continues to be improved through practice (Richard, 1998: 17).

The importance of reading: The most important reasons for reading are:

- Reading is a child's habit of kindness, love, and understanding of the views of others.

- She develops the queen of thought, and tells the child of a world full of opportunities and possibilities, which makes him fly wherever he wants, and dreams of anything he likes Reading passionately gives the child the ability to imagine, and to look after. - Good readers acquire a better sense of language, speaking, writing, and behavior.

- The Queen of Excellent Reading enables children to endure trauma and personal problems, without affecting their academic potential (Leonhardt, M. 1997: 11).

Reading functions:

Some of the most prominent reading functions, the most important of which are:

- Communication: It is the main function, from which the other functions branch, the origin is that we read to achieve 
communication with others who are separated from them by time and space.

- Intellectual and emotional development: by reading, human thought grows, expands its knowledge, enriches its experiences, refines its emotions, and refines its conscience.

- Fun and entertainment: Reading are a good way to enjoy leisure, and to eliminate boredom and preoccupation in moments of loneliness and loneliness. (Ammar, 1432:96)

Reading objectives at primary and middle school:

Al-Sharbji (2005) indicates that the reading objectives are limited to: 1. Subjective goals: the quality of the individual's pronunciation, his or her performance, the understanding of the meaning, his representation, and the acquisition of as much information and experience as possible, to satisfy the individual's needs for independence, selfconfidence, discovery, communication with others and their participation in ideas and feelings, as well as the development of the individual's inclinations, interests, and the use of leisure time and enjoyment.

2. Social goals: the ability of the individual to read and to employ her skills in his or her working life, in order to achieve social adjustment and the ability to deal positively and productively.

3. Educational/cognitive goals: Being able to read skills contributes to the progress of the learner's achievement and mental development, through which the learner receives adequate answers to the questions he raises, or confronts during learning, helps him to solve his problems, develop his linguistic outcome, train him for correct expression, and the resulting tendency to read, and to develop high-level reading habits. The reading material derives its primary objectives from the general objectives of teaching Arabic in basic education, and the Ministry of Knowledge (1422) stated in the Educational Goals document that the objectives of its education in the upper grades of primary school are:

- Pupil M is able to listening skills and manners.

- He develops his wealth from vocabulary, and new compositions.

- Learn about some of the arts of expression in Arabic.

- His ability to read correctly the Qur'an and prophetic hadiths is increased.

- He is able to read boldly, fluently, and the representation of meaning.

- Develops the skill of reading speed with a readable understanding. 
- Acquires silent reading skills, eye reading without moving lips, understanding and tracking meaning.

- Conjures up the ideas he has read, and reformulates them in his own way.

- He has a level of expression in accordance with his mental development.

- Tends to read freely, and turns his free time into a useful pleasure.

- Develops its ability to think properly (Al-Sharbji, 2005: 41).

4. The purpose of reading: Students read texts for a variety of purposes and objectives, including: reading to acquire new information, reading to perform a task, reading for absorption, reading for pleasure, reading for study and achievement (Al-Seliti, 2012: 84). It can be said that meeting or exceeding the objectives of formative and final reading at the level or within the classroom means that pupils with the knowledge and skills they need to read a variety of books and materials with understanding are also able to use reading as a tool to deepen knowledge of difficult academic content across a variety of educational fields, and the degree of instruction sought to develop basic reading skills must be direct and directly related to the level of these pupils below class. Not only that, but educational resources must be allocated to help these students develop the skills needed to read at the two-stage learning level, but teachers must modify the instructions to meet students' needs in understanding thematic texts and materials.

Third- Primary education: the postpreparatory education phase, which replaced basic education from 2004, became five years old (Al-Hussein, 2008: 2).

The primary education Stage: This is a stage from Starting from the age of 6 to 11 years of age and at which the pupil receives an education in the primary school, a stage at which the pupil's acquired language and behavior is reconstituted. In This research, the age of pupils from 9 to 11 years of age has been determined, which is a stage the pupil has the ability to read well.

Fourth- Concept of intermediate education: is the stage of study that mediates the stages of primary and preparatory education and the duration of four-year study and includes students between the ages of 11 and 15 year (Mahmoud, 2008: 453-486).

The intermediate education Stage: This is a stage from Starting from the age of 12 to 15 years from the age of the pupil. In It, It fêles physical maturity and relative autonomy, a stage in which the process of understanding and cognition increases as a result of certain experiences in which the student tends to form directions and 
principles about life and society and the tendency to read and the love of knowledge.

Fifth- The concept of the student: which is the first axis and the last goal of all the processes of education, for which the school is established and equipped with all the means, it must be that all these huge efforts that are made in various fields for the benefit of the student, must have the goal of forming his mind, body, soul, knowledge, and directions (Turky, 1999: 112).

\section{Method and Tools:}

\section{Method:}

The method means these methods and methods that the researcher will have to in the process of collecting data, so we adopted in our study the descriptive method which is the description and interpretation of what is an object, and the collection of data in both qualitative and quantitative types about the phenomenon in question in order to analyze and interpret them in order to draw conclusions and reach generalizations (Daoudi, 2007: 81) The descriptive approach can be defined by Abdel-Al (2004:166) as 'a survey focused on a phenomenon as it exists in the present, intended to diagnose it, detect its aspects and determine the relationships between Its elements and other phenomena, and indicates that the descriptive method of research' is a form of analysis and scientific interpretation organized to describe a specific phenomenon or problem, and its quantify by collecting data and codified information about the phenomenon, or problem, classifying, analyzing and subjecting it to careful study (Solomon, 2014: 131).

The study Sample:

It was represented by the total number of students registered in the external library in the city its 500 are from various educational levels, the sample was selected from the two stages of primary and intermediate education by the intentional method, their ages range between 9 and 15 years old, and their total number is 246 .

Research limits:

Research limits can be defined as follows:

- Spatial boundaries: This study was conducted in some of the primaries and averages of the city of Dar chioukh and the Public Library

- Temporal boundaries: The field side was completed during March and April 2017

- Human boundaries: The study sample consisted of (246) pupils (123) pupils, 140 pupils in the middle and 106 from primary education and the following table showing the relative 
International Journal of Childhood, Counselling, \& Special Education (CCSE), Volume1, Issue: 2, December: 2020, pp.185-203

distribution of the research sample:

Table (1): The relative distribution of the research sample by gender

\begin{tabular}{|c|c|c|c|c|c|c|}
\hline \multirow[t]{2}{*}{$\begin{array}{c}\text { Educational } \\
\text { Stages } \\
\text { Gender }\end{array}$} & \multicolumn{2}{|c|}{$\begin{array}{l}\text { Educational } \\
\text { Primary }\end{array}$} & \multicolumn{2}{|c|}{$\begin{array}{l}\text { Educational } \\
\text { Middle }\end{array}$} & \multicolumn{2}{|l|}{ Total } \\
\hline & number & Percentage & number & Percentage & number & Percentage \\
\hline Male & 62 & $\% 25.20$ & 61 & $\% 24.79$ & 123 & $\% 50$ \\
\hline female & 78 & $\% 31.70$ & 45 & \%18.29 & 123 & $\% 50$ \\
\hline Total & 140 & $\% 56.91$ & 106 & $\% 43.08$ & 246 & $\% 100$ \\
\hline
\end{tabular}

Source: spss $_{25}$

From the table obtained above, the ratios of male and female distribution are totally equal to $50 \%$, while there is a disparity in the distribution of primary school ratios of $43.08 \%$ and the average level of education $56.91 \%$.

Study tools and their psychometric properties:

1- Measure of pupils' tendency to read: This measure was prepared by Adawi Abd al-Zahra and Attia Samira 2008 consisting of 26 specific items with three alternatives to the answer, such as the following (often, to a certain extent- rarely) corrected by the following answers (3-2-1) to become the lowest level corresponding to the value of 26 and the largest score corresponding to the value 78, divided into three areas:

- Subjective factors: consisting of 10 paragraphs

- Promotional factors from the school: consisting of 8 paragraphs
- Encouraging factors from family and friends: it consists of 8 paragraphs. The researchers explained the level of estimate of the answers on the scale as follows:

1. High tilt score $(2.34-3)=61-79$

2. Medium tilt score $(1.67-2.33)$ $=44-61$

3. Low tilt score $(1-1.66)=26-43$

2- The psychometric characteristics of the scale: Psychometric specialists believe that honesty is the only characteristic that determines the aspects of the test and that an honest test is highly correlated with the actual conduct that was intended to measure it, i.e. honesty, that the test be able to measure what is put in place to measure it in the sense that the test is closely related to the attribute it measures (Al-saied. 2006: 17-19.) To ensure the validity of the scale, we applied the scale to the individuals of the study sample, calculating the coefficient of honesty and stability in several ways: 
International Journal of Childhood, Counselling, \& Special Education (CCSE), Volume1, Issue: 2, December: 2020, pp.185-203

2.1- Believe the scale:

- Discriminatory Honesty (Peripheral Comparison): The ability of the scale to distinguish between the two ends of the property that it measures where the scale is applied to the group of examiners and then arranges the grades obtained descending or ascending, then compares the two contradictory groups located on both ends of the property, and uses the "T" test to indicate the differences between the two averages calculated for calculating the honesty of the measure on the discriminatory honesty, where the grades were ranked from the highest to the highest number of distribution and $27 \%$ of the total (the lowest number of individuals was $27 \%$ of the distribution and $27 \%$ of the total distribution was taken.(16) Individuals, and then (T) was calculated to see the differences between the two groups (Abde Al-Halim, 2006: 250), and the following table explains this:

Table (2): represents the results of the honesty of the measure in a discriminatory manner.

\begin{tabular}{lllllllc}
\hline \multicolumn{1}{c}{ Size variable } & $\begin{array}{c}\text { Comparisons } \\
\text { groups }\end{array}$ & $\mathrm{N}$ & $\overline{\mathrm{X}}$ & $\mathrm{S} 2$ & $\mathrm{~T}$ & $\mathrm{Df}$ & sig \\
\hline $\begin{array}{l}\text { the level of tendency } \\
\text { of students and their } \\
\text { attitudes towards } \\
\text { reading }\end{array}$ & Lower Group & 16 & 50.31 & 2.05 & & 30 & $\begin{array}{c}0.000 \\
\text { statistically } \\
\text { Source: } \text { spss } 25\end{array}$ \\
\hline
\end{tabular}

We note from the table obtained that: the value $(\mathrm{t})$ was 11.40 at the degree of freedom (30) at the level of statistical indication (0.000), there are statistically significant differences in the scale between the two groups, in favor of the upper group, the scale has a discriminatory capacity, with the upper group averaged 63.87 while the minimum group averaged 50.31 , which confirms that the scale is correct.
The sincerity of internal consistency:

The sincerity of internal consistency is one of the most important types of honesty that can be used to verify the sincerity of the tool, and to verify the sincerity of internal consistency we calculated the correlation of the degree of each axis to the overall degree of the scale, and it turns out that there is a correlation between each axis with the overall degree of the scale as all these dimensions are honest at the 
level of indication (0.000), therefore the measure is true.

Stability of the scale:

The common definition of stability confirms that it indicates the possibility of relying on the measuring instrument or on the use of the test, which means that the stability of the test is to give the same results continuously if the test is used more than once under similar conditions, i.e. stability indicates that when the test is repeated we get stable results (Fatima, 2002:14), the researchers adopted a set of methods in calculating the stability of the scale:

1. Cronbach Alpha M: The Cronbach Alpha coefficient is one of the indicators of the internal consistency of the scale, the Alpha coefficient represents the average coefficient resulting from the fragmentation of the test in different ways, the variability of each scale line and then the sum of variations, as well as the variation of the overall grade of the scale, and requires that the scale lines measure only one attribute (Al-Saied. 2006: 9), the data was processed in a cronbach alpha method for the scale, so the results were that the stability factor was 0.89 per measure, which indicates stability and These values are close to the one, they are high and indicate the high stability of the scale and therefore it is constant.

2. Calculation of the stability of the scale in the split-half method: The Pearson correlation coefficient is calculated between the two halves of the test using the Guttman equation, we have adopted in calculating the stability of the half-hash method and ensuring consistency in the Guttman way, and the table summarizes the results of data processing in the halffragmentation manner as follows:

Table (3): Represents the results of the scale stability factor

\begin{tabular}{lccccccc}
\hline \multicolumn{1}{c}{ Size variable } & $\mathbf{N}$ & $\overline{\mathrm{X}}$ & $\mathbf{S}^{2}$ & \multicolumn{3}{c}{ The stability factor } \\
\cline { 6 - 8 } & & & & & $\begin{array}{c}\text { Before } \\
\text { correction }\end{array}$ & $\begin{array}{c}\text { After } \\
\text { correcting }\end{array}$ & $\begin{array}{c}\text { Correction } \\
\text { method } \\
\text { Guttman }\end{array}$ \\
$\begin{array}{l}\text { the level of } \\
\text { tendency of }\end{array}$ & Individual & 13 & 27.62 & 3.08 & 0.797 & 0.887 & \\
$\begin{array}{l}\text { students and their } \\
\text { attitudes towards }\end{array}$ & Marital & 13 & 28.17 & 3.14 & & & \\
$\begin{array}{l}\text { reading } \\
\text { Total }\end{array}$ & 26 & 55.78 & 5.90 & & & \\
& & & & & &
\end{tabular}

Through the results of the table obtained, we note that: the value of the measure stability factor in the half-retail method reached $(0.797)$ before correction and after correction in the Guttman manner the value reached (0.887), which is 
International Journal of Childhood, Counselling, \& Special Education (CCSE), Volume1, Issue: 2, December: 2020, pp.185-203

therefore a high value of the constant measure.

Statistical methods:

We have adopted some statistical methods in order to facilitate the process of presentation, analysis and interpretation to reach the results of the study that we will produce and can be clarified as follows:

1. Apply the centrality measures of (arithmetic average, standard deviation).

2. Study the significance of the differences by applying, test ' $T$ ' to indicate the differences between averages, and the statistical processing of the data was done using the statistical program package in the social sciences (spss25).
View, analyze, discuss and interpret the results:

1. Presentation, analysis and discussion of the first hypothesis: The text of the hypothesis: "We expect the level of tendency of students and their attitudes towards reading at the stage of primary education and intermediate it in the city of Dar chiouck in Algeria to be median"; To confirm the validity of the hypothesis, the average and the standard deviation of each area of the scale were calculated as the average values of ]2.34-3[ representing the high inclination score, from ]1.67-2.33 [ representing the average inclination, and from [11.66]the slope is weak, and the following table shows this:

Table (4): Represents the arithmetic average and the standard deviation of the dimensions of the scale

\begin{tabular}{lccccc}
\hline \multicolumn{1}{c}{ Size variable } & $\mathrm{N}$ & $\overline{\mathrm{X}}$ & $\mathrm{S}^{2}$ & Estimate & Ranking \\
\hline Subjective factors & 246 & 2.09 & 1.04 & Average & Second \\
Encouraging factors from school & 246 & 2.18 & 1.26 & Average & First \\
& 246 & 2.09 & 1.28 & Average & Third \\
Encouraging factors from family and friends & 246 & 2.12 & 2.67 & Average & $/ / /$ \\
Total & & & & & \\
Source: spss 25 & & & & & \\
\hline
\end{tabular}

We note from the table above: The variation areas of the tendency of students and their attitudes towards reading at the stage of primary education and intermediate it in the city of Dar chiouck in Algeria, while the level of inclination of primary and middle school pupils is achieved with an average estimate of an mean of 2.12 and a deviation of 2.67, with encouraging factors from school in the first ranking at an average level with an mean calculation of 2.18 and a deviation of 1.26 , while subjective factors in the second ranking at an average level with an mean calculation of 2.09 and a deviation of 1.04 , and encouraging 
factors from family and friends are in third ranking at an average level with an mean of 2.09 and a deviation of 1.28 .

Which stated that "We expect the level of tendency of students and their attitudes towards reading at the stage of primary education and intermediate it in the city of Dar chiouck in Algeria to be median", was accepted.

This result can be attributed to important years of medium childhood in which primary school pupils are believed to work in a developmental manner in what Piaget described as the formal operational stages. At this stage, basic literacy, numeracy and conceptual skills are also acquired and learning; As the student's selfacademic and social perceptions gradually develop with advancing age and pressures of peer influence begin to appear during the early school years, the most universally recognized jobs in schools are the transfer of knowledge and skills that enable the learner to successfully participate in community institutions. In two stages (primaryintermediate), where schools are interested in developing literacy, speaking and computing skills, in most cases, the teacher guides pupils in groups of age or a certain level, using a specific set of educational materials, and the academic results of this public function are assigned to the highest priority; Independent of other community institutions, the interaction between home, family and school is the most obvious example of the interaction between the social system, especially since pupils of this age control many of the tasks of school monitoring and control during the main part of the day, even before and after school; however, the educational effects at the primary level have been studied much lower than those in middle school, although the organization of two levels of school sites is extremely different unlike middle school, Pupils in primary schools remain in one classroom with one teacher most of the day, unlike middle school pupils, distributed through sections, regiments and multi-teacher syllabuses, and primary schools are often nearby schools, conditions in which middle-class pupils lead to a high degree of compatibility between home and school environments, and this may enhance the impact of both, as there is often a lack of conformity between domestic and school environments.

2. Presentation, analysis, discussion and interpretation of the second hypothesis: the text of the hypothesis: "There are statistically significant differences at the level of significance $(\alpha=0.05)$ in the level of tendency of students and their attitudes towards reading at the stage of primary education and intermediate it in the city of Dar chiouck in Algeria according to the 
International Journal of Childhood, Counselling, \& Special Education (CCSE), Volume1, Issue: 2, December: 2020, pp.185-203

variable gender"; to verify this hypothesis, the averages and standard deviations of the level of

inclination of pupils were calculated, then the calculation of ' $\mathrm{T}$ ' and the following table shows this:

Table (5): Represents the arithmetic average, standard deviation and t- test

\begin{tabular}{lccccccc}
\hline \multicolumn{1}{c}{ Size variable } & gender & $\mathrm{N}$ & $\overline{\mathrm{X}}$ & $\mathrm{S}^{2}$ & $\mathrm{~T}$ & $\mathrm{Df}$ & sig \\
\hline $\begin{array}{l}\text { the level of tendency } \\
\text { of students and their } \\
\text { attitudes towards }\end{array}$ & Male & 123 & 55.73 & 6.92 & 134 & 244 & 0.179 \\
$\begin{array}{l}\text { reading } \\
\text { Source: } \text { spss } 25\end{array}$ & & & & & & N S \\
\hline
\end{tabular}

The above table states that:

The $t$-values in the table indicate that there is no significant difference was found between the two gender ( $T=1.34 ; \alpha=0.05$ ) on the level of tendency of students and their attitudes towards reading, sig value is 0.179 Since sig value is bigger than the significant level (0.05). Based on these computed statistical values, it can be claimed that, There is not differences at the level of $(\alpha=0.05)$ the level of tendency of students and their attitudes towards reading at the stage of primary education and intermediate it in the city of Dar chiouck in Algeria according to the variable gender, which is not statistically significant, and therefore there aren't statistically significant differences at the level of significance $(\alpha=0.05)$ in the level of tendency of students and their attitudes towards reading at the stage of primary education and intermediate according to the variable gender.

Which stated that "There aren't statistically significant differences at the level of significance $(\boldsymbol{\alpha}=0.05)$ in the level of tendency of students and their attitudes towards reading at the stage of primary education and intermediate it in the city of Dar chiouck in Algeria according to the variable gender", wasn't accepted.

This result can be attributed to the ways in which teachers and teachers organized classrooms in the classroom to teach reading, where the result reflected the number of educational groups and the size of the groups identified by specific characteristics such as class size and the number of low-qualified pupils in the classroom also that teachers transferred pupils from one group to another during the school year largely and based on their good performance as a key determinant of the willingness of the individual to read, which is also the main determinant of the amount of subjects covered in the Reading texts and ultimately the amount learned by the students of the two stages, both male and female. This finding can also be attributed to the fact that 
International Journal of Childhood, Counselling, \& Special Education (CCSE), Volume1, Issue: 2, December: 2020, pp.185-203

building a strong basis for reading at the primary and middle school levels is essential for learning to read and is essential for being an active participant in society and the workforce. Written language is a vital means of communication, access to information, the development of cultural, social and personal identity and national awareness, and to understand other points of view, students face a range of language models written in a variety of settings; at home, school and community, and reading texts using descriptive and emotional language also opens up worlds. New, real or imaginary, so that pupils of both genders can enjoy it.
3. Presentation, analysis, discussion and interpretation of the third hypothesis: The text of the hypothesis is "There are statistically significant differences at the level of significance $(\alpha=0.05)$ in the level of tendency of students and their attitudes towards reading at the stage of primary education and intermediate it in the city of Dar chiouck in Algeria according to the variable Educational stage"; To verify this hypothesis, the averages and standard deviations of the student's inclination level were calculated according to the school stage, then the ' $T$ ' calculation and the following table shows this:

Table (6): Represents the arithmetic average, standard deviation and t-test

\begin{tabular}{lccccccc}
\multicolumn{1}{c}{ Size variable } & & $\mathrm{N}$ & $\overline{\mathrm{X}}$ & $\mathrm{S}^{2}$ & $\mathrm{~T}$ & $\mathrm{Df}$ & $\mathrm{sig}$ \\
\hline $\begin{array}{l}\text { the level of tendency of } \\
\text { students and their attitudes } \\
\text { towards reading }\end{array}$ & intermediate & 140 & 54.42 & 6.08 & 2.00 & 244 & 0.046 \\
& & & & & & & $\mathrm{~S}$ \\
Source: spss 25 & Primary & 106 & 56.14 & 7.29 & & & \\
\hline
\end{tabular}

It is adopted from the table above that:

The $t$-values in the table indicate that there is significant difference was found between the two Educational stage $(T=2.00 ; \alpha=0.05)$ on the level of tendency of students and their attitudes towards reading, sig value is 0.046 Since sig value is smaller than the significant level (0.05). Based on these computed statistical values, it can be claimed that, There is differences at the level of $(\alpha=0.05)$ the level of tendency of students and their attitudes towards reading at the stage of primary education and intermediate it in the city of Dar chiouck in Algeria according to the variable Educational stage, which is statistically significant, and therefore there are statistically significant differences at the level of significance $(\alpha=0.05)$ in the level of tendency of students and their attitudes towards reading at the stage of primary education and intermediate according to the variable 
International Journal of Childhood, Counselling, \& Special Education (CCSE), Volume1, Issue: 2, December: 2020, pp.185-203

Educational stage in favor primary education.

Which stated that "There aren't statistically significant differences at the level of significance $(\boldsymbol{\alpha}=0.05)$ in the level of tendency of students and their attitudes towards reading at the stage of primary education and intermediate it in the city of Dar chiouck in Algeria according to the variable Educational stage", was accepted. for the school stage the impact of the level of inclination of primary and intermediate reading pupils due to the education Stage. This finding can be attributed to the fact that through the primary stage students are increasingly able to use images, symbols, concepts and rules, as is their vocabulary, this stage covers most of what he calls the concrete stage and the beginning of the formal processes, a period when the student is expected to acquire a wide range of academic skills and develop the ability to solve increasingly complex problems. It is clear that the environment has a significant impact on cognitive development; While it is likely that middle school schools have not kept pace with the ability to enhance access to their ability to improve quality, rapid expansion has put a heavy strain on school management, teaching staff, overall quantity and quality of effective classroom teaching, resulting in a large number of busy multi-classroom schools, increased student/teacher ratios and lower reading test scores.

\section{Results and Discussion}

Insert your results in this section in the same format (font, size, line spacing). A summary of the collected data should be presented in the form of proportions or totals. Then, the data analysis procedure should be explained both using text and illustrative means (the tables and figures referred to in the Appendix) in accordance with the method and instruments presented above. After presenting the results, their contents can be evaluated and interpreted statistically and psychologically in the light of the hypotheses, and they are compared to what others have found in previous studies.

\section{Conclusion}

In the end, it can be said that partially fulfilled hypotheses and through this research paper we aim through this approach to encourage all pupils to the habit of reading on a large scale and in many times we expect teachers to do everything in their power to enhance pupils' love of reading, also the goal is to encourage all students Pupils choose and read books independently, in which they select, through elementary school and outside it, what they tend to see, so they discover writing those interests or make them think or make them laugh. These feelings that they 
experience are an inspiration to read more, from here the results have resulted in the following: The level of tendency of students and their attitudes towards reading at the stage of primary education and intermediate it in the city of Dar chiouck in Algeria stage to be median, while we recorded that There aren't statistically significant differences at the level of significance $(\alpha=0.05)$ in the level of tendency of students and their attitudes towards reading at the stage of primary education and intermediate it in the city of Dar chiouck in Algeria according to the variable gender. There are statistically significant differences at the level of significance $(\alpha=0.05)$ in the level of tendency of students and their attitudes towards reading at the stage of primary education and intermediate it in the city of Dar chiouck in Algeria according to the variable Educational stage. Finally, and based on what has been presented in the theoretical heritage, previous studies and the field side, it can be said that the study has achieved some of its hypotheses and thus achieves its objectives by answering the questions raised and discussing, analyzing and interpreting its results. Therefore, the results of the study can be generalized to a sample only The proposals: We can present procedural and scientific prospects that can be suggested through the following:
- The literacy development of pupils during middle childhood.

- The social background to develop students' reading skills.

- Improving the reading quality of middle school students.

- National standards for improving and enhancing reading among students of the three educational stages.

- Establishing effective learning standards and developing reading among students.

\section{References}

Abde al-Bari, Husni (1999). Fundamentals in Teaching and Teaching the Arabic Language, Alexandria Modern Arab Bureau.

Abde Al-Halim, Mahmoud (2006). Statistics and Measurement of Education and Psychology, Alexandria: House of Knowledge.

Adawi, Abd al-Zahra and Attia Samira Hassan (2008). Revealing the level of penchant for teacher sit-in students towards reading, Journal of Misan Researches, 5(9), 257-288

Al-Hassan, Hisham (2005). Methods of Teaching Children Reading and Writing, 1st Edition, Jordan: House of Culture.

Al-Hussein, Qarsas (2008). Evaluation of the process of educational supervision in the elementary education stage according to teachers' opinions 
published MA thesis, University of Mentoury, Constantine.

Al-Saied, Muhammad Abu Hashem Hasan (2006). Psychometric properties of measuring tools in psychological and educational research using SPSS, Riyadh: King Saud.

Al-Seliti, Firas (2012). Interactive Teaching and Critical Reading: Indicators, Activities, and Evaluation. Irbid, Jordan: The Modern World of Books.

Al-Sharbji, Riyad Badri (2005). Reading problems from childhood to adolescence, diagnosis and treatment, Amman: Dar Al-Safa.

Ammar, Sam (1432H), Modern Trends in Teaching the Arabic Language, Beirut: The Message Foundation.

Fatima, awed and Mervat Ali (2002). Basis and Principles of Scientific Research, 1st Edition, Egypt: AlRadaa Art Library and Printing Press

Daoudi, Mohamed and Boufatah, Mohamed (2007). Methodology for writing scientific research and university theses, 1st Edition, Djelfa: The Eurasian Library.

Doeing. John and, Leong.chechekan, (1982). Psychology of reading, New York, Macmillan.

Mahmoud, Kazem Mahmoud (2008). Self-efficacy and its relationship to anarchic behavior among middle school students. Prof.
Magazine. (72), College of Education - Ibn Rushd - University of Baghdad, pp. 453-486.

Leonhardt, M (1997). 99 Ways to Get Kids to Love Reading, translated by Ibrahim Al-Ghamry, Amman: The International House of Ideas.

Richard, Anderson (1998). A Reading Nation, Translated by: Shawqi Al-Saied Al-Sharifi, Cairo: International House.

Nazzal, Hamid Shakir (2002). Some of the factors affecting students 'tendency towards reading and the correlation of this tendency with their general achievement and achievement in the Arabic language Educational Sciences Studies, 1 (25), 181-204.

Solomon, Abd al-Rahman Saied (2014). Research Methods, 1st Edition, Cairo: The World of Books. Turky, Rabeh (1999). Fundamentals of Education, The National Book Foundation, 2nd Edition, Algeria: University Publications Bureau.

Al-bakr, Fahd Bin Abdel Kareem (2013). Evaluation of First Year Intermediate Students' Performance Level of Creative Reading, Journal of the Humanities and Social Sciences, 31, 13-55.

Al-Haiali, Ahmed Muhammad Noori Mahmoud (2011). The Effect of Using Peer Tutoring Teaching Strategy on Developing Some oral Reading Skills by Special Education 
International Journal of Childhood, Counselling, \& Special Education (CCSE), Volume1, Issue: 2, December: 2020, pp.185-203

Pupils in Reading, College of Basic Education Researches Journal, 11 (2), $1-36$.

Hassan, Saad Alwan (2003). The effect of the two types of aloud and social reading on reading achievement and literary appreciation of middle school students, College of Education (Ibn Rushd), University of Baghdad, unpublished doctoral thesis.

Mousa, Mohamed Mahmoud (2007). The Effectiveness of Using Computers in developing Reading Comprehension of Eleventh Secondary Grade Students in UAE, Reading \& Knowledge Journal, No,34, Ain Shams University, Egypt.
Al-Shammari, Zeid Bin Muhalhl (2020), The effectiveness of metamemory based on proposed enrichment activities in developing reading comprehension skills of first middle Grade Students, Journal of the Human Sciences, vol.5.

Al-Lafi, Said Abdullah (2000). A proposed reading program in light of contemporary issues and its impact on the development of critical thinking among high school students, research published at the 12th Scientific Conference of the Egyptian Society for Curriculum and Teaching Methods, Curriculum education and thinking development, Faculty of Education, Ain Shams University, 158-193. 